\title{
The benefits of climate change mitigation in integrated assessment models: The role of the carbon cycle and climate component
}

\author{
Andries F. Hof ${ }^{1}$, Chris W. Hope ${ }^{2}$, Jason Lowe ${ }^{3}$, Michael D. Mastrandrea ${ }^{4}$, Malte \\ Meinshausen $^{5,6}$, Detlef P. van Vuuren ${ }^{1,7}$ \\ Corresponding author: Andries Hof, PBL Netherlands Environmental Assessment Agency \\ E-mail: Andries.hof@pbl.nl. Tel: +31 30274 4529. Fax: +31 302744464 \\ ${ }^{1}$ PBL Netherlands Environmental Assessment Agency, PO Box 303, 3729 AH Bilthoven, \\ The Netherlands \\ ${ }^{2}$ Cambridge Judge Business School, University of Cambridge, Trumpington Street, \\ Cambridge CB2 1AG, United Kingdom \\ ${ }^{3}$ Met Office, Hadley Centre, Reading University, Reading, Berkshire, RG6 6AH, United \\ Kingdom \\ ${ }^{4}$ Woods Institute for the Environment, Stanford University, Yang \& Yamazaki \\ Environment \& Energy Building - 4205, 473 Via Ortega, Stanford, CA, 94305, USA \\ ${ }^{5}$ Potsdam Institute for Climate Impact Research (PIK), PO Box 6012 03, Telegrafenberg \\ A31, D-14412 Potsdam, Germany \\ ${ }^{6}$ School of Earth Sciences, University of Melbourne, Victoria 3010, Australia \\ ${ }^{7}$ Utrecht University, Department of Geography, Utrecht, The Netherlands
}

\begin{abstract}
Integrated Assessment Models (IAMs) are an important tool to compare the costs and benefits of different climate policies. Recently, attention has been given to the effect of different discounting methods and damage estimates on the results of IAMs. One aspect to which little attention has been paid is how the representation of the climate system may affect the estimated benefits of mitigation action. In that respect, we analyse several well-known IAMs, including the newest versions of FUND, DICE and PAGE. Given the role of IAMs in integrating information from different disciplines, they should ideally represent both best estimates and the ranges of anticipated climate system and carbon cycle behaviour (as e.g. synthesised in the IPCC Assessment reports). We show that in the longer term, beyond 2100, most IAM parameterisations of the carbon cycle imply lower $\mathrm{CO}_{2}$ concentrations compared to a model that captures IPCC AR4 knowledge more closely, e.g. the carbon-cycle climate model MAGICC6. With regard to the climate component, some IAMs lead to much lower benefits of mitigation than MAGICC6. The most important reason for the underestimation of the benefits of mitigation is the failure in capturing climate dynamics correctly, which implies this could be a potential development area to focus on.
\end{abstract}

Keywords: Integrated Assessment Models, Climate change, Carbon cycle, Climate model, Mitigation, Uncertainty 


\section{Introduction}

Integrated Assessment Models (IAMs) describe many of the complex relations between environmental, social and economic systems that determine future climate change and the effectiveness of climate policy. They are increasingly used to compare the costs and benefits of alternative mitigation proposals, and also the balance between emission reductions to avoid climate change and adaptive responses to cope with its consequences (see e.g. Harremoës and Turner 2001; Hope 2005; Nordhaus 2010; Weyant et al. 1996). To explicitly represent all of the known and quantifiable processes that contribute to the future state of the climate and associated impacts would be an immense challenge, so IAMs typically use relatively simple equations or sets of equations to simulate the behaviour of the socio-economic and environmental systems. In many IAMs, the carbon cycle and climate components, for instance, consist of only a few equations (Goodess et al. 2003). Van Vuuren et al. (2011) and Warren et al. (2010) have shown that the different representations of carbon cycle and climate response within IAMs can lead to large differences in the climate outcomes of these models.

This paper builds on this work by focusing on the consequences of the representation of the carbon cycle and climate system in IAMs for their evaluation of the benefits of climate policy. It is not our aim to explain in detail the differences in climate outcomes (since this was done by van Vuuren et al. (2011) and Warren et al. (2010)), but to show the consequences of these differences for the cost-benefit applications of IAMs. Earlier, Schultz and Kasting (1997) have focused on the implications of the carbon cycle representation of one IAM (the 1994 model version of DICE; a model that has now been updated) for optimal emission reductions. This study, instead, looks at several IAMs and the implications of the differences in both the climate and carbon cycle components across the models. For comparison, we also look at other critical assumptions that determine the outcome of cost-benefit analyses such as baseline assumptions, discounting and damage function (Hof et al. 2008; Hope 2006b; Mastrandrea and Schneider 2004; Tol 2008).

The approach we have taken in this paper is to evaluate the sensitivity of the benefits of mitigation in a range of well-known economic IAMs to climate and carbon cycle assumptions. The benefits of mitigation (the difference between damage costs between a baseline scenario and a low emission trajectory) are a major factor for determining the preferred mitigation strategy. In our assessment, we only look at economic IAMs (and not on more complex process-based IAMs) because the latter generally do not estimate the benefits of mitigation in monetary terms.

It is not our aim to exactly explore the boundaries of uncertainty or rigorously define the shape of the probability distribution of outcomes. Instead we want to elucidate the degree to which the different outcomes of economic IAMs are determined by the way they represent the carbon cycle and climate system. The IAMs included in this study are 
PAGE-2002 (Hope 2006a), PAGE09, DICE-2007 (Nordhaus 2008) ${ }^{1}$, DICE-2009², FUND 2.8 (Tol 2006), FUND 3.3 (Anthoff and Tol 2009) ${ }^{3}$ and MERGE 5.1 (Manne and Richels 2006).

As the purpose of IAMs is to integrate existing information in different fields, one may argue that IAMs should focus on best-guess values for the carbon cycle and climate system and/or to represent the uncertainty ranges reported by assessments that synthesise the full spectrum of the relevant literature, specifically the IPCC Assessment Reports. In order to obtain a reasonable indication of both best guess values and such uncertainty ranges, we use the MAGICC6 climate model (Meinshausen et al. 2011a; Meinshausen et al. 2011b), which is specifically calibrated towards IPCC AR4 results in terms of radiative forcing efficiencies, climate and carbon cycle responses. While MAGICC is still a simple model in comparison to high-complexity general circulation models (GCMs) or coupled dynamic vegetation land and ocean carbon cycle models, for the variables of interest for this study, Meinshausen et al. (2011a; 2011b) have shown that MAGICC6 can successfully emulate the current generation of GCMs (Meehl et al. 2005) as well as carbon cycle models that took part in the C4MIP intercomparison (Friedlingstein et al. 2006). Here, we use a joint distribution of MAGICC6's radiative forcing and climate response parameters that has been constrained by comparison with historical observations, i.e. the "illustrative default" case described in Meinshausen et al. (2009).

This paper is organised as follows. In the next section we describe the methodology, and give an overview of how the carbon cycle and climate response are modelled in the IAMs that are analysed in this study. In Section 3, we present the results and Section 4 draws conclusions.

\section{Method}

IAMs simulate the chain of processes that begins with a description of human activities that give rise to greenhouse gas emissions. These emissions lead to an increase in greenhouse gas concentrations in the atmosphere. In IAMs, this is calculated by some representation of the carbon cycle and by additional (usually simple) chemistry parameterisations for atmospheric abundances of other non- $\mathrm{CO}_{2}$ gases and aerosol precursors. The changes in greenhouse gas and aerosol concentrations, in turn, lead to a radiative forcing. The climate component of the IAMs calculates the effect on near surface temperature, and in some cases sea level rise. All IAMs analysed in this paper include a module to calculate the costs of reducing greenhouse gas emissions compared to the baseline and a module to calculate the monetary damages of climate change. In order to compare the costs and benefits of mitigation over time, a discount factor is

\footnotetext{
${ }^{1}$ Available at http://nordhaus.econ.yale.edu/

${ }^{2}$ Available at http://nordhaus.econ.yale.edu/. Note that the DICE-2009 model is a beta-version.

${ }^{3}$ Both FUND 2.8 and FUND 3.3 are available at http://www.mi.unihamburg.de/FUND.5679.0.html
} 


\begin{tabular}{|c|c|c|c|}
\hline & Carbon cycle & $\begin{array}{l}\text { equilibrium temperature } \\
\text { response }\left({ }^{\circ} \mathrm{C}\right)\end{array}$ & $\begin{array}{l}\text { transient } \\
\text { temperature } \\
\text { response }\end{array}$ \\
\hline $\begin{array}{l}\text { DICE- } \\
2007\end{array}$ & $\begin{array}{l}\text { Three-reservoir model } \\
\text { (atmosphere, upper oceans } \\
\text { and biosphere, deep oceans), } \\
\text { calibrated to match carbon } \\
\text { cycle in MAGICC } 4.1\end{array}$ & 3.0 & $\begin{array}{l}\text { Function of RF } \\
\text { with lag effect and } \\
\text { heat loss from } \\
\text { atmosphere to } \\
\text { oceans }\end{array}$ \\
\hline $\begin{array}{l}\text { DICE- } \\
2009\end{array}$ & $\begin{array}{l}\text { As in DICE-2007, but re- } \\
\text { calibrated according to } \\
\text { MAGICC } 5.3 \text { and EMICs, } \\
\text { leading to higher } \\
\text { concentrations }\end{array}$ & 3.0 & $\begin{array}{l}\text { As in DICE-2007, } \\
\text { but slower } \\
\text { response } \\
\text { according to AR4 } \\
\text { results }\end{array}$ \\
\hline FUND 2.8 & $\begin{array}{l}\text { Impulse-response function } \\
\text { based on } 2 \mathrm{CO}_{2} \text { pulse (Maier- } \\
\text { Reimer and Hasselmann, 1987) }\end{array}$ & 2.5 & $\begin{array}{l}\text { Follows } \\
\text { equilibrium } \\
\text { temperature with } \\
\text { a delay } \\
\text { parameter }^{1} \text { of } 50 \\
\end{array}$ \\
\hline FUND 3.3 & As in FUND 2.8 & $\begin{array}{l}\text { gamma distribution ( } 8.127, \\
0.3508 \text { ), leading to mode } 2.5 \\
\text { and mean } 2.85\end{array}$ & $\begin{array}{l}\text { As in FUND } 2.8, \\
\text { but with } \\
\text { triangular } \\
\text { distribution of } \\
\text { delay parameter } \\
(25,75,125)\end{array}$ \\
\hline $\begin{array}{l}\text { MERGE } \\
5.1\end{array}$ & $\begin{array}{l}\text { Impulse-response function } \\
\text { based on } 1.25 \times \mathrm{CO}_{2} \text { pulse } \\
\text { (Maier-Reimer and } \\
\text { Hasselmann, 1987) }\end{array}$ & 2.5 & $\begin{array}{l}\text { As in FUND 2.8, } \\
\text { but with delay } \\
\text { parameter of } 26\end{array}$ \\
\hline $\begin{array}{l}\text { PAGE- } \\
2002\end{array}$ & $\begin{array}{l}\text { Single impulse-response } \\
\text { function with 'natural } \\
\text { emissions' term to represent } \\
\text { carbon cycle feedback }\end{array}$ & $\begin{array}{l}\text { triangular } \\
\text { distribution }(1.5,2.5,5) \text {, } \\
\text { yielding a mean of } 3.0\end{array}$ & $\begin{array}{l}\text { As in FUND } 2.8 \text {, } \\
\text { but with } \\
\text { triangular } \\
\text { distribution of } \\
\text { delay parameter } \\
(25,50,75)\end{array}$ \\
\hline PAGE09 & $\begin{array}{l}\text { As in PAGE-2002, but with } \\
\text { 'CO2 concentration gain' to } \\
\text { represent carbon cycle } \\
\text { feedback }\end{array}$ & $\begin{array}{l}\text { transient climate response } \\
\text { with triangular distribution } \\
(1,1.3,2.8) \text { leading to a mean } \\
\text { of } 3.0 \text {, a } 90 \% \text { range of } 1.8 \text { to } \\
4.7 \text {, a min of } 1.3 \text { and a max of } \\
6.7\end{array}$ & $\begin{array}{l}\text { As in PAGE-2002 } \\
\text { but with } \\
\text { triangular } \\
\text { distribution of } \\
\text { delay parameter } \\
(10,30,65)\end{array}$ \\
\hline MAGICC6 & $\begin{array}{l}\text { Land and ocean carbon cycle } \\
\text { including } \mathrm{CO}_{2} \text { fertilisation, } \mathrm{CO}_{2} \\
\text { chemistry feedback (ocean) } \\
\text { and temperature feedbacks, } \\
\text { calibrated towards aggregated } \\
\text { carbon pools and fluxes of } \\
\text { C4MIP high-complexity carbon } \\
\text { cycle models. }\end{array}$ & $\begin{array}{l}\text { joint distribution of } \\
\text { parameters with a marginal } \\
\text { climate sensitivity } \\
\text { distribution resembling IPCC } \\
\text { AR4 estimates (median } 3 \text { and } \\
\text { likely range between } 2.0 \text { and } \\
4.5) \text {. See "illustrative default" } \\
\text { case in Meinshausen et al. } \\
\text { (2009) }\end{array}$ & $\begin{array}{l}\text { See Fig. } 1 \text { in } \\
\text { Meinshausen et } \\
\text { al. (2009) }\end{array}$ \\
\hline
\end{tabular}

${ }^{1}$ A delay parameter of $x$ means that given a sustained change in the level of radiative forcing the half life in terms of reaching the new equilibrium is $\ln (2) / x$ years.

Table 1. Main characteristics of the selected IAMs with respect to the carbon cycle and climate system modelling (adapted from van Vuuren et al., 2011) 
used. The discount factor enables representing all future costs and benefits in a single number, namely the net present value of these future costs and benefits.

Earlier, Van Vuuren et al. (2011) described for each model how they have represented the carbon cycle and climate system. This is summarised in Table 1, with the new versions of DICE, PAGE and FUND added.

We investigate the marginal effect of different climate and carbon cycle representations on the benefits of mitigation by varying parameter values for one specific link in the causal change - with everything else being set to the same default values (Figure 1; default values are marked). This transparent approach highlights the contribution of uncertainty in each individual step - but ignores possible non-linear interactions between the steps (e.g. the impact of a slow climate response is different for a high or a low discount rate).

- Insert Figure 1 abut here -

As indicated in the introduction, we not only look into the uncertainty introduced by the carbon cycle and climate system representation, but for comparison also vary the baseline, damage function and discount rate as these factors are known to be important for the outcomes of cost-benefit analysis. To simplify the comparison, we do not run the original models - but recode a stand-alone version of the climate/carbon cycle parts of the models in $\mathrm{MyM}^{4}$ (Beusen et al. 2011); the exceptions being both versions of the PAGE IAMs and MAGICC6 climate model, of which the original model codes are run. In the case of DICE-2007 and DICE-2009, we have tested the recoded models and found they produce results identical to the original models. The equations of the stand-alone versions are available online in the Electronic Supplementary Material.

In the experiments, the linking of the different steps as described above can be performed easily in the recoded models. Taking the default case as an example, we can easily run the recoded FUND 3.3 carbon cycle model driven with emissions data as input into the DICE-2009 climate model. Next, the DICE-2009 damage function can be used to estimate the damages of temperature projections over time. Finally, a 2.5\% fixed discount rate is applied to determine the present value of these damages. In this set-up, it is relatively simple to replace any of these default elements for the carbon cycle, climate system, damage function and discount rate with an alternative set. For MAGICC6 and PAGE, the same approach is used but using soft-linkages (i.e. exchanging data files).

\footnotetext{
${ }^{4} \mathrm{MyM}$ is an integrated environment for the development, visualization and application of simulations of dynamic systems. More information can be found on http://www.my-m.eu/
} 


\subsection{Emission scenarios}

As input into our model runs, we use standardised emission scenarios. We focus on the calculated damage costs of a baseline scenario, with no explicit mitigation policy, and of an ambitious mitigation scenario. The difference in damages between these scenarios gives the benefits of mitigation. ${ }^{5}$

In our calculations, the default baseline is the SRES B2 illustrative marker scenario and the alternative the SRES A2 illustrative marker scenario (Nakicenovic et al. 2000). The A2 scenario is comparable to the new RCP8.5 - the highest scenario of a the Representative Concentration Pathways (RCP) set, recently developed to allow standardised climate model runs as input into IPCC $5^{\text {th }}$ Assessment Report (Moss et al. 2010) . The B2 scenario, in contrast, lies between the two middle RCPs (RCP4.5 and RCP6).

The contrasting ambitious mitigation scenario used in this study is an overshoot scenario developed by the IMAGE model for the ENSEMBLES project to stabilise radiative forcing in the long run at $2.6 \mathrm{~W} / \mathrm{m}^{2}$, reaching a 2100 radiative forcing level of $2.9 \mathrm{~W} / \mathrm{m}^{2}$ (Johns et al. 2011; Lowe et al. 2009). In this scenario, $\mathrm{CO}_{2}$ emissions peak in 2015 at about $9 \mathrm{GtC}$ and decline sharply to $0.5 \mathrm{GtC}$ at the end of the century. This scenario is among the lowest scenarios in the literature; approximately $1 \mathrm{GtC} / \mathrm{yr}$ higher than the RCP3-PD by the end of the $21^{\text {st }}$ century, with RCP3-PD being the lowest scenario in the RCP-set. The scenarios run until 2100 , after which we assume that emissions remain constant at the 2100 level.

Figure 2 shows the $\mathrm{CO}_{2}$ emissions in the different scenarios over time. We consider it appropriate to confine ourselves to $\mathrm{CO}_{2}$ only, since this is the most important gas in terms of radiative forcing. Moreover, in some of the models covered here (the two DICE versions) non- $\mathrm{CO}_{2}$ gases are not modelled. Instead, an exogenous radiative forcing term is added to take into account non- $\mathrm{CO}_{2}$ emissions. However, we do acknowledge that temperature variations driven by other greenhouse gases and aerosols would modify the carbon cycle and climate system response.

- Insert Figure 2 about here -

\subsection{Carbon cycle representation}

The first step in the causal chain from emissions to climate change damages is the calculation of the atmospheric $\mathrm{CO}_{2}$ concentration as a function of emissions. Table 1 summarises the representation of the carbon cycle in the IAMs included in our analysis.

\footnotetext{
${ }^{5}$ More specifically, the benefits of mitigation are presented in this paper as the discounted difference of climate change damages in the reference and mitigation scenario as share of the present value of GDP, over the time period 2010-2200
} 
Van Vuuren et al. (2011) describe experiments that analyse the behaviour of each of these models (except DICE-2009, PAGE09 and FUND 3.3, which were not yet available at that time).

In both DICE-2007 and DICE-2009, the carbon cycle is represented by different carbon pools, representing the atmosphere, the upper ocean and biosphere (combined), and the deep ocean. The parameters in DICE-2009 have been revised in order to match the MAGICC 5.3 model and earth system models of intermediate complexity.

In contrast, MERGE 5.1, FUND 2.8 and FUND 3.3 represent the entire carbon cycle by an impulse-response function based on Maier-Reimer and Hasselmann (1987). The functions of Maier-Reimer and Hasselmann consist of five integrals, each of which deal with a certain fraction of the emissions and are characterised by a typical exponential decay time. In the original paper, three sets of parameters were provided for different sizes of pulse emission, corresponding to increases in the carbon dioxide concentration to $1.25 x, 2 x$ and $4 x$ the pre-industrial $\mathrm{CO}_{2}$ concentration, respectively. The need for different sets of parameters, depending on the size of the pulse, is a consequence of non-linearity of the carbon cycle response. Given the need of simplification, however, the IAMs only use one parameter set. The MERGE model uses the parameters derived from the $1.25 \times \mathrm{CO}_{2}$ pre-industrial pulse, while both versions of the FUND model use the parameters corresponding to the $2 \times \mathrm{CO}$ pre-industrial pulse (note that the parameters in FUND 3.3 are based on normal probability distributions, with mean values the same as in FUND 2.8). In practise, this means that in FUND, $13 \%$ of total emissions remain forever in the atmosphere, while $10 \%$ is removed in 2 years. In MERGE, $14 \%$ of total emissions remain forever in the atmosphere, while $9 \%$ is removed in 1.7 years.

Also the two versions of the PAGE model (2002 and 2009) use a pulse-response function - but here using only one exponential decay time, in combination with a fraction of the emissions that is removed immediately. PAGE-2002 and PAGE09 include an explicit representation of carbon cycle feedbacks, by a 'natural emissions' term that increases as a function of temperature in PAGE-2002, and by a ' $\mathrm{CO}_{2}$ concentration gain' that increases as a function of temperature in PAGE09. In PAGE09, the strength of the carbon cycle feedback is about the same as in PAGE-2002 for high emission scenarios, but lower than in PAGE-2002 in the long term for stringent abatement scenarios.

The FUND 2.8 model (which is identical to the mean settings of the carbon cycle of FUND 3.3) is used as default setting. We compare the results of the individual IAMs with the $90 \%$ confidence interval of the carbon cycle component of MAGICC6. The MAGICC model has a process description of carbon flows between the terrestrial vegetation stock, the atmosphere and the ocean. The model has been calibrated in order to represent the behaviour of ocean and land carbon pools and fluxes of individual more complex models from the C4MIP model comparison exercise, as described in Meinshausen et al. (2011a; 2011b). 


\subsection{Climate representation}

The climate model component of IAMs defines the relationship between greenhouse gas concentration and temperature. Damages are actually determined by the transient temperature response, which in all assessed IAMs is a function of the equilibrium temperature response and a measure of the response time of the climate system (see Table 1). Again, Van Vuuren et al. (2011) describe the results of a set of experiments that describe the performance of the climate models in each of the IAMs, mostly in terms of the level and timing of warming.

The equilibrium temperature response is denoted by the equilibrium climate sensitivity (Knutti and Hegerl 2008), i.e. the equilibrium change in global mean temperature resulting from a radiative forcing corresponding to a doubling of atmospheric $\mathrm{CO}_{2}$ concentration. In GCMs the climate sensitivity is an emergent quantity but in simple climate models (including MAGICC6) and all of the IAMs included in our analysis except PAGE09, climate sensitivity is exogenously determined (in addition, MAGICC6 includes parameters to capture time-variable effective climate sensitivities). According to the IPCC (2007) the likely range of climate sensitivity is between $2^{\circ} \mathrm{C}$ and $4.5^{\circ} \mathrm{C}$, with a best estimate of $3^{\circ} \mathrm{C}$. In both DICE models, the climate sensitivity is set at $3.0^{\circ} \mathrm{C}$; in FUND 2.8 and MERGE 5.1 at $2.5^{\circ} \mathrm{C}$. The climate sensitivity in FUND 3.3 is given by a gamma probability distribution with a mean of $2.85^{\circ} \mathrm{C}$ and a mode of $2.5^{\circ} \mathrm{C}$. PAGE-2002 denotes climate sensitivity by a triangular probability distribution with a minimum of $1.5^{\circ} \mathrm{C}$, a mode of $2.5^{\circ} \mathrm{C}$, and a maximum of $5^{\circ} \mathrm{C}$. In PAGE09, the climate sensitivity is calculated from the transient climate response and feedback response time. The MAGICC6 climate model is a more complex model, here constrained by a comparison with historical observations, resulting in a joint distribution of underlying parameters as described in Meinshausen et al. (2009). Here, we use the "illustrative default" case that implies a median of climate sensitivity close to $3^{\circ} \mathrm{C}$ and a likely range in the marginal distribution close to the IPCC Fourth Assessment Report estimate of 2 to $4.5^{\circ} \mathrm{C}$ - matching the posterior distribution in Frame et al. (2006), derived from a uniform prior on the transient climate response.

The investigated IAMs calculate the actual temperature response by applying some kind of delay function on top of the equilibrium temperature calculation. Both versions of the PAGE model, both versions of the FUND model and MERGE 5.1 describe the actual temperature as a constant proportion (the delay parameter) of the equilibrium temperature and the temperature of last year. The level of the delay parameter differs across the models. MERGE 5.1 uses a delay parameter of 26 (meaning that the actual temperature at a particular time is calculated as $1 / 26$ of the equilibrium temperature at that time and $25 / 26$ of the realised temperature from the previous year). FUND 2.8 uses a delay parameter of 50 , resulting in a much slower transient temperature response than in MERGE 5.1. In FUND 3.3, the delay parameter is determined by a triangular distribution function with a minimum of 25 , a mode of 75 , and a maximum of 125 . PAGE-2002 also adopts a triangular distribution function, but with a minimum of 25 , a mode of 50 , and a maximum of 75 , while in PAGE09 the minimum is 10 , the mode is 30 and the maximum is 65 . Finally, DICE-2007 and DICE-2009 do not adopt a single delay parameter, but instead the transient temperature response depends on both a delay 
parameter and the heat loss from the atmosphere to oceans. The transient response time of MAGICC6 is more complex than a simple lag function, modelled by a diffusionupwelling-entrainment ocean model (Meinshausen et al., 2009).

It should be noted that the uncertainty in equilibrium climate sensitivity and the earth system's response times are (partially) correlated. A higher equilibrium climate sensitivity necessarily suggests a slower temperature response time to explain the current level of climate change (although this correlation is complicated by the uncertainty in actual forcings, in particular aerosol forcings). Therefore, the differences in response time among the IAMs should be interpreted in the light of the differences in equilibrium climate sensitivity between the IAMs. For instance, MERGE 5.1 combines a relatively low equilibrium climate sensitivity with a relatively fast transient temperature response. In the analysis, we use the combination of climate sensitivity and climate response for each model as a set.

In our default calculations, we use the climate model of DICE-2009, simply because this is the most recent one. Again, we have included the confidence interval of the MAGICC6 climate model for comparison.

\subsection{Damage functions}

There are large uncertainties involved in projecting climate change damages, partly originating from the uncertainties in damage functions themselves that are used in IAMs (Tol et al. 2004). Here, we briefly look into the possible effect of these differences on the benefits of mitigation to put the influence of different representations of the climate system and carbon cycle in context.

The cost-benefit IAMs analysed in this study differ with respect to the sectoral and regional detail and of the impact categories included in the damage estimates. Global damages in DICE are calculated using a single power law function of global temperature increase, which is based on regional damages by impact category as projected by the RICE model (Nordhaus and Boyer 2000). FUND, MERGE and PAGE do not include a global damage function: global damages are obtained by summing regional damages.

Of all IAMs included in our study, FUND has the most disaggregated damage estimates: damages are projected for a wide range of impact categories (but excluding the costs of catastrophic events) and for 16 world regions. These damage projections are not only a function of global mean temperature, but also of the rate of temperature change and per capita income. PAGE includes separate damage functions for market, non-market and catastrophic impacts. MERGE includes a market and a non-market damage function. Damages in MERGE are a function of both temperature change and per capita income with damages increasing sharply above a certain per capita income threshold.

With regard to sectoral coverage, the most important distinction between the IAMs is whether or not they include the probabilities of catastrophic events. PAGE and DICE include this probability, and these models arrive at higher damage estimates than FUND, which does not take into account the probabilities of catastrophic events. 
Given the large differences in methodology of calculating damages, we have chosen to use the simple global damage function of DICE-2007 (which is the same as DICE-2009) for the default setting. Of all IAMs included in our analysis, this function results in the highest mean damages (Hof et al. 2008; Smith et al. 2001). For a representation of low damage estimates, as a contrast, we use a simplified version of the equity weighted damage function of Tol as depicted in Figure 19-4 in Smith et al. (2001). The equations of both damage functions are available online in the Electronic Supplementary Material. The two damage functions bracket the whole range of the damage estimates from the IAMs included in our analysis, except for the extremes of the probability distributions in both PAGE model versions ${ }^{6}$. Moreover, these two functions have a very different shape. The DICE function is used as the default representation. For a more detailed comparison of damage functions of different IAMs, we refer to earlier publications of Warren et al. (2006), Stern (2006), Watkiss et al. (2005), IMF (2008), and Smith et al. (2001).

\subsection{Discounting method}

Different views exist on what constitutes the best discounting method, if any, for intergenerational cost-benefit analyses such as climate change policy (Hoel and Sterner 2007; Howarth 2003; Nordhaus 2007; Stern 2006; UK Treasury 2003; Weitzman 2001, 2007). Most studies use the Ramsey equation for determining the discounting method. This equation states that the discount rate should be equal to the rate of pure time preference plus the negative of the elasticity of the marginal utility of consumption times the per-capita growth rate of consumption. Nordhaus uses the estimated market return on capital as basis for the appropriate discounting method for both versions of the DICE model. In practice, this means that the rate of pure time preference is chosen at $1.5 \%$ per year and the elasticity of the marginal utility of consumption at -2 , leading to an average discount rate in the first half of the century of $5.5 \%$ per year in the DICE models (Nordhaus 2008). Some argue that a lower discount rate should be used for climate change policy analysis. For instance, Stern (2006) follows the argument made by among others Ramsey (1928), Harrod (1948) and Solow (1974), that the welfare of future generations should be treated the same as the current one on ethical grounds. Therefore, Stern calibrates the Ramsey equation using a rate of pure time preference of $0.1 \%$ and an elasticity of the marginal utility of consumption of -1.0 , resulting in a discount rate of $1.3 \%$ in the Stern Review (Stern 2006). Other arguments for using a lower discount rate than the market interest rate are made by Ackerman et al. (2009), Hoel and Sterner (2007), Howarth (2003), Weitzman (2007) and van den Bergh (2010). Hoel and Sterner argue that if the relative price of the ecosystem service rises, the discount rate used for these services should be lower. Ackerman et al., Howarth and Weitzman all argue that the discount rate applied to climate change policy should be lower than the market rate because of uncertainty in future consumption. Finally, van den Bergh argues that individual time preference is a wrong analogy for social discounting, since societies are immortal (implicitly recognised by Stern).

\footnotetext{
${ }^{6}$ PAGE uses probability distributions to model climate change damage given the large uncertainties of the (shape of the) damage function.
} 
To reflect the range of different positions, we apply the discounting methods of Nordhaus and Stern. Apart from these two discount rates, we also include the discounting method for long-term appraisals recommended by the UK Green Book (UK Treasury, 2003). This is a decreasing discounting method, starting at 3.5\% per year and gradually declining towards $2.0 \%$ per year after 130 years. For our default calculations, we use a simple constant discount rate of $2.5 \%$.

\section{Results}

First, we discuss the sensitivity of the individual steps in the causal chain - baseline emissions, carbon cycle component, climate component, and discounting method - on climate change damages and the benefits of mitigation. Subsequently, we compare the sensitivity of these individual steps with each other.

\subsection{Sensitivity of baseline emissions}

For analysing the sensitivity of the baseline emissions, we analyse the impact of using the default B2 emission scenario and the alternative baseline (A2) (see Figure 2). The other components in the cause-effect chain of climate change are held constant at their default values (see Figure 1). The higher $\mathrm{CO}_{2}$ emissions in the $\mathrm{A} 2$ baseline result in a higher temperature increase. As expected, the benefits of the mitigation scenario (equal to the difference in damages between the baseline and mitigation scenario) are also much larger for the A2 baseline: the benefits are $0.9 \%$ of GDP for the B2 baseline and $2.1 \%$ of GDP for the A2 baseline (Figure 3 ).

- insert Figure 3 about here -

\subsection{Sensitivity of the carbon cycle}

The carbon cycle model determines the $\mathrm{CO}_{2}$ concentration in the atmosphere as a result of emissions. Van Vuuren et al (2011) ran several, more generic experiments with most of the models. To understand the impacts of the carbon cycle on the damage costs, we briefly discuss the impacts of the different representation of the carbon cycle here for the $\mathrm{CO}_{2}$ concentration (note that the newest versions of DICE, FUND and PAGE were not included in van Vuuren et al., 2011) - before moving to the additional information on the consequences for temperature and damage costs.

The carbon cycle models of all IAMs, with the exception of PAGE-2002, lead to similar concentration pathways given a fixed emission pathway (Figure 4). 
In the mitigation scenario, the range of the peak in $\mathrm{CO}_{2}$ concentrations of all IAMs (except PAGE-2002) is 445 ppm to 453 ppm (the 90\% uncertainty range of PAGE09 being 432 to 462 ppm). This peak is reached around 2050 in these IAMs. PAGE-2002 forms an exception as the relative strong carbon cycle feedback (see Van Vuuren et al., 2011) lead to a situation in which concentration does not peak but keeps rising to 459 to $623 \mathrm{ppm}$ in 2200 in the mitigation scenario (which is above the MAGICC6 uncertainty range). This effect has been revised downwards in PAGE09. In the short to medium term, the concentration levels resulting from the carbon cycle models of the IAMs are within the confidence interval of MAGICC6. By 2200, however, most IAMs arrive at lower concentrations than MAGICC6. A reason for these lower concentrations in the IAM carbon cycle models than in MAGICC in the long run has already been shown in van Vuuren et al. (2011) by a simple pulse experiment: the simple carbon cycle parameterisations of some IAMs do not capture the slower removal rates at higher $\mathrm{CO}_{2}$ concentrations and the possible saturation of the available carbon sinks. This was reported earlier Schultz and Kasting (1997) for the DICE model.

- insert Figure 4 about here -

The $\mathrm{CO}_{2}$ concentration levels for the baseline scenarios are also similar according to the carbon cycle models of the different IAMs. PAGE-2002 forms, again, the exception with higher concentrations in the long term (2200). Just as for the mitigation scenario, in the long term the carbon cycle models of the IAMs lead to lower concentrations than MAGICC6 (PAGE-2002 forms again an exception). However, intercomparisons of the last generation of high complexity carbon cycle models (C4MIP) was limited to 2100 and one higher monotonously increasing scenario (SRES A2) only. The emulation beyond this calibration space is hence inherently uncertain - albeit applying physical process parameterisations, even though of very simplified nature, instead of mere statistical fits and tests with earlier longer-term carbon cycle intercomparisons (Orr 2002) provide some confidence in the validity of these longer-term emulations.

Figure 5 shows how these differences in $\mathrm{CO}_{2}$ concentrations affect global temperature increase (according to the DICE-2009 climate model). As expected due to the small differences in concentrations resulting from the carbon cycle models of IAMs, temperature differences are small: in 2200, the range of temperature increase in the baseline is 3.6 to $3.8^{\circ} \mathrm{C}$ relative to pre-industrial levels. PAGE-2002 is the only exception with a temperature increase of $4.1^{\circ} \mathrm{C}$ (with a $90 \%$ probability range of 3.5 to $4.6^{\circ} \mathrm{C}$ ). As can be expected from the concentration results, the temperatures projected by the carbon cycle models of the IAMs are lower than projected by MAGICC6 in the long term (except for PAGE-2002).

- insert Figure 5 about here - 
Figure 6 shows damage estimates resulting from the temperature projections (using the DICE damage function). The present values of the damage estimates in the baseline are (as expected) very similar across most of the models. All estimates are well within the range of MAGICC6- related estimates, because the difference in the present value of damages is not strongly affected by long term temperature differences due to discounting. The differences in the present value for the mitigation scenario are also small - again with the exception of PAGE-2002.

- insert Figure 6 about here -

The resulting impact on the benefits of mitigation is correspondingly small and all estimates are within the uncertainty range estimated by our default IAM elements in combination with MAGICC6' carbon cycle. All carbon cycle models lead to benefits of about 0.9 to $1 \%$ of GDP, except both PAGE models, which result in lower mean benefits of about $0.8 \%$. For PAGE-2002, this is due to relative high damage projections for the mitigation scenario (a result of the high carbon cycle feedback); for PAGE09, this is due to the relatively low damage projections of the baseline scenario.

\subsection{Sensitivity of the climate model}

The sensitivity of the climate model has been analysed by providing the climate models with the same trajectory of $\mathrm{CO}_{2}$ concentrations, resulting from the carbon cycle model of the FUND model (see Figure 1). Again, generic experiments looking at the climate model only were run by van Vuuren et al. (2011), and we use the results of their experiments to explain the results found here. As shown in Table 1, PAGE-2002, PAGE09 and FUND 3.3 use a probabilistic function for both the climate sensitivity and transient temperature response. For the PAGE model versions, we focus on the $90 \%$ confidence interval and for FUND 3.3, we include the mean and the mode (best guess) of these functions in our analysis.

Figure 7 shows that the climate models lead to considerable differences in temperature outcomes, especially for the baseline. The FUND 2.8 climate model leads to a temperature increase of less than $3.3^{\circ} \mathrm{C}$ by 2200 in the baseline, whereas the climate model of PAGE09 leads to an increase of almost $4^{\circ} \mathrm{C}$ for the mean (with a large uncertainty range of 2.5 to $6^{\circ} \mathrm{C}$ ). The MAGICC6 $90 \%$ uncertainty range for 2200 is also large $\left(2.5\right.$ to $\left.4.9^{\circ} \mathrm{C}\right)$, which indicates the uncertainties in our current understanding of the climate system. The climate models of all IAMs fall within this range, although all except both versions of PAGE are in the lower half of this range. The finding that the climate models of MERGE, FUND 2.8 and the mode of FUND 3.3 lead to the lowest temperatures is expected, since these models assume the lowest climate sensitivity (see Table 1). In the shorter term, both FUND model versions even lead to temperatures below the MAGICC6 uncertainty range - for FUND 2.8, this replicates the finding by van 
Vuuren et al. (2011). FUND 3.3 leads to even lower temperatures than FUND 2.8; a direct consequence of the slower response time in FUND 3.3.

- insert Figure 7 about here -

In the mitigation scenario, temperature differences between the models are very small. Interestingly, the 2200 temperature outcome of the mean version of FUND 3.3 now exceeds those of the DICE model versions. This again can be explained by the relatively slow response time in FUND 3.3., because of which mitigation is less effective. The relatively fast response time of MERGE 5.1 leads to higher temperatures in 2050, but lower temperature in $\mathbf{2 2 0 0}$ compared to the FUND models. With the exception of the year 2050, the climate models of all IAMs fall within the uncertainty range of MAGICC6 in the mitigation scenario.

The relatively small difference in temperature outcome between the mitigation and baseline scenario according to the FUND model versions implies that there is a smaller benefit of mitigation compared to other models, as can be seen in Figure 8. The benefits of the mitigation scenario (in terms of avoided damage using the DICE damage function) of the FUND models are somewhere between 0.4 and $0.5 \%$ of GDP. For the DICE-2007 and PAGEO9 climate models, the benefits are about twice as high. The climate model of DICE-2009 leads to slightly lower benefits, a result of the somewhat slower temperature response time in DICE-2009. The benefits of the climate module in MERGE 5.1, finally, are between those in the FUND and DICE models. Even though MERGE 5.1 assumes a relatively low climate sensitivity of $2.5^{\circ} \mathrm{C}$, the temperature response time is relatively fast, which leads to the higher benefits compared to the FUND model versions. The benefits of mitigation according to the climate models of DICE and PAGE09 are close to the central range as projected by our default IAM elements in combination with MAGICC6 as climate module. For the climate modules included in the other models, especially FUND, the projections are on the low end or even below the uncertainty range of MAGICC6.

- insert Figure 8 about here -

As already noted above, the large differences in the benefits of mitigation caused by different climate models can be caused by differences in climate sensitivity and differences in temperature response time. To test which of these two factors are more important, we ran the climate models again - but this time, with the same climate sensitivity of $3.0^{\circ} \mathrm{C}$ for all models. As both DICE and PAGE model versions and MAGICC6 already assume a (mean) climate sensitivity of $3.0^{\circ} \mathrm{C}$, only the results of MERGE and FUND differ in this run. The empty bars of Figure 8 show the results of setting the climate sensitivity to $3.0^{\circ} \mathrm{C}$ in MERGE and FUND. The mean and mode of FUND 3.3 lead 
to the same results, since the mode and mean of the temperature response time is the same (see Table 1).

As expected, increasing the climate sensitivity to $3.0^{\circ} \mathrm{C}$ leads to higher damages for both the mitigation and baseline scenario. The net effect leads to higher benefits of mitigation. MERGE moves from the lower end of the MAGICC6 uncertainty range to the middle and gives now very similar results to DICE and the mean of both PAGE model versions. This implies that for MERGE, the relatively low climate sensitivity explains why the benefits of mitigation are lower than for PAGE and DICE. The benefits of FUND 2.8 also increase substantially, although they are still in the lower end of the MAGICC6related uncertainty range. For FUND 3.3, the increase in the benefits of mitigation is very small. This implies that for FUND 3.3, climate dynamics (i.e. the slow temperature response time) largely explains why the benefits of mitigation are small compared to the climate models of other IAMs and MAGICC6. Indeed, Table 1 already showed that the temperature response time of FUND 3.3 is relatively slow - leading to much lower discounted damages in the baseline but only slightly lower discounted damages in the mitigation scenario.

\subsection{Sensitivity of the damage function}

We examine the possible effect of the damage estimates by comparing the results of the default DICE damage function with the alternative damage function based on the FUND model (see Section 2.4). These two damage functions cover the whole range of damage estimates of the IAMs included in our analysis, except for the extremes of the probability distributions in both PAGE models. The results are shown in Figure 9. According to the alternative damage function, the mitigation scenario leads to small benefits. The damages in the baseline are also much smaller: about $0.3 \%$ of GDP against more than $1.4 \%$ of GDP for the DICE damage function. The benefits of mitigation are therefore smaller according to the alternative damage function (about $0.4 \%$ of GDP) than according to the DICE damage function (about $0.9 \%$ of GDP).

- insert Figure 9 about here -

\subsection{Sensitivity of the discounting method}

For analysing the effect of the discounting method on the benefits of the mitigation scenario, we computed the difference in discounted impacts between the mitigation and baseline scenario for the different discounting methods included in our study. The results are shown in Figure 10. As expected, the discounting method of Nordhaus (relatively high discount rates) leads to the lowest benefits of mitigation: slightly less than $0.6 \%$ of GDP. The benefits resulting from the UK Green Book discounting method are about $0.9 \%$ of GDP. This is comparable to the results of a constant $2.5 \%$ per year 
discount rate. Finally, the discounting method as applied in the Stern Review leads to the highest benefits of mitigation of $1.5 \%$ of GDP.

- insert Figure 10 about here -

\subsection{Synthesis}

Figure 11 compares the relative importance of the different assumptions in the causeeffect chain of climate change benefits. The purpose is to assess the relative impact of different climate change/carbon cycle representations in IAMs. We compare the differences due to different representation of the carbon cycle and climate system in IAMs to those by other factors.

- insert Figure 11 about here -

Different assumptions of both baseline emissions and discount rate result in a fairly wide range of possible values for the benefits of the mitigation scenario. For the high A2 baseline, the difference in present value of climate impacts are $2.1 \%$ of GDP compared to the mitigation case, instead of $0.9 \%$ for the more average B2 baseline. It should be noted that we have not looked into the question whether the mitigation scenario can actually be reached from the A2 baseline. In any case, a higher baseline (like A2) also leads to higher mitigation costs - and for cost-benefit analysis the difference between mitigation costs and avoided damages are important. These trends thus work in opposite direction. The strong effect of the discounting method on the present value of the benefits of the mitigation scenario is also not surprising, since this has been found in numerous other studies as well (Hof et al. 2008; Hope 2006b; Tol 2008).

An important finding of this study is that the representation of the climate model has an almost equally important impact. The MAGICC6 model results indicate the influence of a fuller range of uncertainty (including the climate sensitivity range) - but the differences between different climate models in IAMs are large as well. Arguably, one may expect IAMs to represent the climate system by a "best guess" response derived from more complex models. Nevertheless, the climate system as represented by the mean calibration of PAGEO9 leads to 2.5 times the benefits as the mode climate model of FUND 3.3. Needless to say, this has a large impact on the outcomes of cost-benefit studies. The effect of different carbon cycle models on the benefits of the mitigation scenario between the IAMs is relatively small (about one third of the effect of different climate models). 


\section{Conclusions and discussion}

This paper analysed how the benefits of climate change mitigation as projected by wellknown IAMs may be influenced by their representation of the carbon cycle and climate system. The main reason for such an analysis is that, while in the past attention has been given to the influence of discounting methods and damage functions to the outcomes of different IAMs, relatively little attention has been given to the influence of the carbon cycle and climate representation. Two recent papers (van Vuuren et al. 2011; Warren et al. 2010), however, have shown that the temperature outcome between climate models in IAMs can differ substantially as a consequence of different carbon cycle and climate system representations. This paper builds on these findings to investigate what these differences imply for the outcome of cost-benefit applications.

The sensitivity of the carbon cycle representation in the IAMs on the benefits of mitigation- equal to the difference in damages between the mitigation scenario and baseline - is small compared to other factors. There are a few reasons for this. First, the differences in $\mathrm{CO}_{2}$ concentration as a result of the carbon cycle differences are relatively small. Second, the differences occur for both the baseline and mitigation scenario - and therefore part of the impact is offset for the indicator we use here. Finally, long-term differences are given much less weight compared to short-term differences due to the discount rate. As a result, even though PAGE-2002 does lead to higher mean temperatures, due to a relatively strong carbon cycle feedback, this only has a small effect on the mean benefits of mitigation. In fact, the carbon cycle model of PAGE-2002 leads to smaller mean benefits of mitigation than according to all of the other IAMs analysed. The mean result and $90 \%$ confidence interval for PAGE09 is very similar. The carbon cycle representations in MERGE 5.1, FUND 2.8, FUND 3.3, DICE-2007 and DICE2009 all lead to similar present values of damages, which are close to the central range as projected by the carbon cycle component of the MAGICC6 climate model. It should be noted that in the long run, there are noticeable differences between those based on the carbon cycle model of MAGICC6 and the carbon cycle models within the IAMs. The carbon cycle models of the IAMs generally lead to lower temperatures in the long term.

In contrast to the impact of the carbon cycle representation, the climate system representation does lead to very different results across IAMs. This seems to be consistent with the fact that the uncertainty in the climate system is much larger than the uncertainty in the carbon cycle (Gregory et al. 2009; Jungclaus et al. 2010). Overall, the climate component of some IAMs leads to temperature outcomes that are below or near the very low end - of the MAGICC6 90\% confidence interval. This is notably the case for the different FUND model versions and can be explained by a relatively slow temperature response time (the main factor for FUND 3.3) and a relatively low climate sensitivity (the main factor for FUND 2.8). This leads to much smaller benefits of mitigation according to the FUND climate model compared to the climate models of the other IAMs. For a discount rate of 2.5\%, this difference can be up to a factor of 2.5 (for higher discount rates, the difference would be smaller). This means that the effect of the (dynamics of the) climate system representation may be almost as high as that of discounting. 
It should be noted that the models examined in this paper do not include an explicit land-use model and therefore do not cover the possible connections between the energy system, land use and impacts on the carbon cycle/climate system. A well-known example of such a feedback is the increased deforestation rate as a consequence of increased use of bio-energy (Searchinger et al. 2008; van Vuuren et al. 2007; Wise et al. 2009).

What does this imply for the recommendations resulting from the different IAMs? Some guidance to policy makers can be given from the results of this paper. So far, discussions on interpretation of IAM results seem to focus more on the differences of their assumptions for socio-economic parameters. We have shown that the elaboration of the climate component in the current IAMs, especially the climate dynamics, does matter strongly for their results as well. In comparing the results of different IAMs, one would not only need to have a look at differences in baseline or the discount rate that has been applied - but also to the climate representation. For instance, the FUND model versions lead to lower mitigation benefits than other IAMs and are very close to the low end of the uncertainty range of the MAGICC6 model. This will automatically imply a higher preferred emission pathway in cost-benefit applications. Given the role of IAMs (integration of information of different disciplines) one may argue that ideally, they would represent both the most likely values (according to expert models) and the ranges.

Acknowledgements The contribution of DVV has been supported by the AMPERE project, cofunded by the European Commission within the $7^{\text {th }}$ Framework Programme. The contribution of AH was supported by the COMBINE project under the same Framework Programme. JLs time on this project was supported by the AVOID programme, which is funded by DECC and Defra.

\section{References}

Ackerman F, J. deCanio S, Howarth RB, Sheeran K (2009) Limitations of integrated assessment models of climate change. Clim Change 95 (3-4):297-315.

Anthoff D, Tol RSJ (2009) The Impact of Climate Change on the Balanced Growth Equivalent: An application of FUND. Environ Resource Econ 43 (3):351-367.

Beusen AHW, de Vink PJF, Petersen AC (2011) The dynamic simulation and visualization software MyM. Environ Modell Softw 26 (2):238-240.

Frame DJ, Stone DA, Stott PA, Allen MR (2006) Alternatives to stabilization scenarios. Geophys Res Lett 33:L14707.

Friedlingstein P, Cox P, Betts R, Bopp L, von Bloh W, Brovkin V, Cadule P, Doney S, Eby M, Fung I, Bala G, John J, Jones C, Joos F, Kato T, Kawamiya M, Knorr W, Lindsay K, Matthews HD, Raddatz T, Rayner P, Reick C, Roeckner E, Schnitzler K-G, Schnur R, Strassmann K, Weaver K, Yoshikawa C, Zeng N (2006) Climate-Carbon Cycle Feedback Analysis: Results from the C4MIP Model Intercomparison. J Clim 19 (14):3337-3353. 
Goodess CM, Hanson C, Hulme M, Osborn TJ (2003) Representing Climate and Extreme Weather Events in Integrated Assessment Models: A Review of Existing Methods and Options for Development. Integr Assess 4 (3):145-171.

Gregory JM, Jones CD, Cadule P, Friedlingstein P (2009) Quantifying carbon cycle feedbacks. J Clim 22 (19):5232-5250.

Harremoës P, Turner R (2001) Methods for integrated assessment. Reg Environ Change $2(2): 57-65$.

Harrod RF (1948) Towards a dynamic economics. Macmillan, London

Hoel M, Sterner T (2007) Discounting and relative prices. Clim Change 84 (3-4):265-280.

Hof AF, den Elzen MGJ, van Vuuren DP (2008) Analysing the costs and benefits of climate policy: Value judgements and scientific uncertainties. Glob Environ Change 18 (3):412-424.

Hope C (2005) Integrated Assessment Models. in Helm D (ed.) Climate Change Policy. Oxford University Press, Oxford.

Hope C (2006a) The marginal impact of CO2 from PAGE2002: an integrated assessment model incorporating the IPCC's five reasons for concern. Integr Assess 6 (1):19-56.

Hope C (2006b) The social cost of carbon: what does it actually depend on? Clim Policy 6 (5):565-572.

Howarth RB (2003) Discounting and uncertainty in climate change policy analysis. Land Econ 79 (3):369-381.

IMF (2008) Climate change and the global economy. World Economic Outlook: Housing and the business cycle. International Monetary Fund, Washington, D.C., pp. 133-190.

IPCC (ed.): (2007) Climate Change 2007: The Physical Science Basis. Contribution of Working Group I to the Fourth Assessment Report of the Intergovernmental Panel on Climate Change, Cambridge University Press, Cambridge, United Kingdom and New York, NY, USA.

Johns TC, Royer JF, Höschel I, Huebener H, Roeckner E, Manzini E, May W, Dufresne JL, Otterå OH, van Vuuren DP, Salas y Melia D, Giorgetta MA, Denvil S, Yang S, Fogli PG, Körper J, Tjiputra JF, Stehfest E, Hewitt CD (2011) Climate change under aggressive mitigation: the ENSEMBLES multi-model experiment. Climate Dynamics. doi:10.1007/s00382-011-1005-5.

Jungclaus JH, Lorenz SJ, Timmreck C, Reick CH, Brovkin V, Six K, Segschneider J, Giorgetta MA, Crowley TJ, Pongratz J, Krivova NA, Vieira LE, Solanki SK, Klocke D, Botzet M, Esch M, Gayler V, Haak H, Raddatz TJ, Roeckner E, Schnur R, Widmann H, Claussen $M$, Stevens B, Marotzke J (2010) Climate and carbon-cycle variability over the last millennium. Clim Past Discuss 6 (3):1009-1044.

Knutti R, Hegerl GC (2008) The equilibrium sensitivity of the Earth's temperature to radiation changes. Nat Geosci 1 (11):735-743.

Lowe JA, Hewitt CD, Van Vuuren DP, Johns TC, Stehfest E, Royer J-F, van der Linden PJ (2009) New Study For Climate Modeling, Analyses, and Scenarios. Eos 90 (21):181188.

Maier-Reimer E, Hasselmann K (1987) Transport and storage of Carbon dioxide in the ocean-an inorganic ocean-circulation carbon cycle model. Clim Dyn 2:63-90.

Manne AS, Richels RG (2006) The role of non-CO2 greenhouse gasses and carbon sinks in meeting climate objectives. Energy J (Special Issue \#3):393-404. 
Mastrandrea MD, Schneider SH (2004) Probabilistic integrated assessment of "dangerous" climate change. Science 304 (5670):571-575.

Meehl GA, Covey C, McAvaney B, Latif M, Stouffer RJ (2005) Overview of coupled model intercomparison project. Bull Am Meteorol Soc 86 (1):89-93.

Meinshausen M, Meinshausen N, Hare W, Raper SCB, Frieler K, Knutti R, Frame DJ, Allen MR (2009) Greenhouse-gas emission targets for limiting global warming to $2^{\circ} \mathrm{C}$. Nature 458 (7242):1158.

Meinshausen M, Raper SCB, Wigley TML (2011a) Emulating coupled atmosphere-ocean and carbon cycle models with a simpler model, MAGICC6 - Part 1: Model description and calibration. Atmospheric Chemistry and Physics 11 (4):1417-1456.

Meinshausen M, Wigley TML, Raper SCB (2011b) Emulating atmosphere-ocean and carbon cycle models with a simpler model, MAGICC6 - Part 2: Applications.

Atmospheric Chemistry and Physics 11 (4):1457-1471.

Moss RH, Edmonds JA, Hibbard KA, Manning MR, Rose SK, Van Vuuren DP, Carter TR, Emori S, Kainuma M, Kram T, Meehl GA, Mitchell JFB, Nakicenovic N, Riahi K, Smith SJ, Stouffer RJ, Thomson AM, Weyant JP, Wilbanks TJ (2010) The next generation of scenarios for climate change research and assessment. Nature 463 (7282):747-756.

Nakicenovic N, Alcamo J, Davis G, de Vries B, Fenhann J, Gaffin S, Gregory K, Grübler A, Jung TY, Kram T, Emilio la Rovere E, Michaelis L, Mori S, Morita T, Pepper W, Pitcher H, Price L, Riahi K, Roehrl A, Rogner H, Sankovski A, Schlesinger M, Shukla P, Smith S, Swart R, van Rooyen S, Victor N, Dadi Z (2000) Special Report on emissions scenarios. Cambridge University Press, Cambridge, UK.

Nordhaus WD (2007) A Review of the Stern Review on the economics of climate change. J Econ Lit 45 (3):686-702.

Nordhaus WD (2008) A Question of Balance: Weighing the Options on Global Warming Policies. Yale University, New Haven.

Nordhaus WD (2010) Economic aspects of global warming in a post-Copenhagen environment. Proc Natl Acad Sci U S A 107 (26):11721-11726.

Nordhaus WD, Boyer J (2000) Warming the World: Economic Models of Global Warming. MIT Press, Cambridge, Massachusetts.

Orr JC (2002) Global Ocean Storage of Anthropogenic Carbon (GOSAC). EurOCMIP-2 Final Report. IPSL/CNRS, France, p. 128.

Ramsey FP (1928) A Mathematical Theory of Saving. Econ J 38:543-559.

Schultz PA, Kasting JF (1997) Optimal reductions in CO2 emissions. Energy Policy 25 (5):491-500.

Searchinger T, Heimlich R, Houghton RA, Dong F, Elobeid A, Fabiosa J, Tokgoz S, Hayes D, Yu TH (2008) Use of U.S. croplands for biofuels increases greenhouse gases through emissions from land-use change. Science 319 (5867):1238-1240.

Smith J, Schnellnhubner H-J, Mirza MQM (2001) Vulnerability to climate change and reasons for concern: a synthesis. in McCarthy JJ, Canziani OF, Leary NA, Dokken DJ, White KS (eds.) Climate Change 2001: Impacts, Adaptation, and Vulnerability. Cambridge University Press, Cambridge, UK.

Solow RM (1974) The economics of resources or the resources of economics. Am Econ Rev 64 (2):1-14. 
Stern N (2006) The Economics of Climate Change, The Stern Review. Cambridge University press, Cambridge, UK.

Tol RSJ (2006) Multi-Gas Emission Reduction for Climate Change Policy: An Application of FUND. Energy J Special Issue \#3:235-250.

Tol RSJ (2008) The Social Cost of Carbon: Trends, Outliers and Catastrophes. Economics 2 (2008-25).

Tol RSJ, Downing TE, Kuik OJ, Smith JB (2004) Distributional aspects of climate change impacts. Glob Environ Change 14 (3):259-272.

UK Treasury (2003) The Green Book: Appraisal and evaluation in central government. TSO, London.

Van den Bergh JCJM (2010) Safe climate policy is affordable -12 reasons. Clim Change 101 (3-4):339-385.

van Vuuren DP, den Elzen MGJ, Lucas PL, Eickhout B, Strengers BJ, van Ruijven B, Wonink S, van Houdt R (2007) Stabilizing greenhouse gas concentrations at low levels: an assessment of reduction strategies and costs. Clim Change 81 (2):119-159.

van Vuuren DP, Lowe J, Stehfest E, Gohar L, Hof AF, Hope C, Warren R, Meinshausen M, Plattner G-K (2011) How well do integrated assessment models simulate climate change? Clim Change 104 (2):255-285.

Warren R, Hope C, Mastrandrea MD, Tol R, Adger N, Lorenzoni I (2006) Spotlighting impacts functions in integrated assessment: Research report prepared for the Stern Review on the economics of climate change. Working Paper 91. Tyndall Centre for Climate Change Research, Norwich.

Warren R, Mastrandrea MD, Hope C, Hof AF (2010) Variation in the climatic response to SRES emissions scenarios in integrated assessment models. Clim Change 102 (3):671685.

Watkiss P, Anthoff D, Downing T, Hepburn C, Hope C, Hunt A, Tol R (2005) The social costs of carbon (SCC) review: methodological approaches for using SCC estimates in policy assessment. Final Report. Defra, London.

Weitzman ML (2001) Gamma discounting. Am Econ Rev 91 (1):261-271.

Weitzman ML (2007) A Review of the Stern Review on the economics of climate change. J Econ Lit 45 (3):703-724.

Weyant J, Davidson O, Dowlatabadi H, Edmonds J, Grubb M, Parson EA, Richels R, Rotmans J, Shukla PR, Tol RSJ, Cline WR, Fankhauser S (1996) Integrated assessment of climate change: An overview and comparison of approaches and results. in Bruce JP, Lee H, Haites EF (eds.) Climate Change 1995: Economic and Social Dimensions. Contribution of Working Group III to the Second Assessment Report of the Intergovernmental Panel on Climate Change. Cambridge University Press, Cambridge.

Wise M, Calvin K, Thomson A, Clarke L, Bond-Lamberty B, Sands R, Smith SJ, Janetos A, Edmonds J (2009) Implications of limiting CO2 concentrations for land use and energy. Science 324 (5931):1183-1186. 


\section{FIGURE CAPTIONS}

Fig. 1 Overview of the default (denoted by $a^{*}$ ) and alternative assumptions

Fig. $2 \mathrm{CO}_{2}$ emission trajectories for the two baseline scenarios used in this study and the mitigation scenario (emissions after 2100 are assume to be constant at the 2100 level)

Fig. 3 Climate change damage for the two baseline scenarios and mitigation scenario, and the difference between those, according to the default assumptions listed in Fig. 1

Fig. 4 Impact of carbon cycle model on concentration levels over time for the $\mathrm{CO}_{2}$-only baseline scenario and mitigation scenario

Fig. 5 Impact of carbon cycle model on global temperature increase over time, keeping the other assumptions listed at their default values as listed in Fig. 1 (Note: the confidence interval of the difference assumes that the distribution of the confidence interval for the baseline and mitigation scenario are the same. This is supported by a comparison of the distribution of confidence intervals between different scenarios of MAGICC6)

Fig. 6 Impact of carbon cycle model on cumulative discounted climate change damage over 20002200 for the baseline and mitigation scenario, and the difference between those

Fig. 7 Impact of climate model on global $\mathrm{CO}_{2}$-induced temperature increase over time, following the $\mathrm{CO}_{2}$-only $\mathrm{B} 2$ baseline and ENSEMBLES mitigation scenario, keeping the other assumptions listed at their default values as listed in Fig. 1

Fig. 8 Impact of climate model on cumulative discounted climate change damage for the baseline and mitigation scenario, and the difference between those

Fig. 9 Impact of the damage function on climate change damage for the baseline and mitigation scenario, and the difference between those

Fig. 10 Impact of the discounting method on climate change damage for the baseline and mitigation scenario, and the difference between those

Fig. 11 Sensitivity of different assumptions on climate change benefits of mitigation 


\begin{tabular}{ccccc} 
Baseline emissions & \multicolumn{1}{c}{ Carbon cycle $\longrightarrow$ Climate response $\longrightarrow$ Damage function $\longrightarrow$ Discounting method } \\
B2* & FUND 2.8 \& 3.3* & DICE-2009* & DICE-2009* & $2.5 \%$ fixed* \\
A2 & DICE-2007 & DICE-2007 & Low alternative & DICE \\
& DICE-2009 & FUND 2.8 & Stern \\
& PAGE-2002 & FUND 3.3 & UK Green Book \\
& PAGE09 & PAGE-2002 & \\
MERGE 5.1 & PAGE09 & \\
& MAGICC 6.0 & MERGE 5.1 &
\end{tabular}


Emissions (GtC)

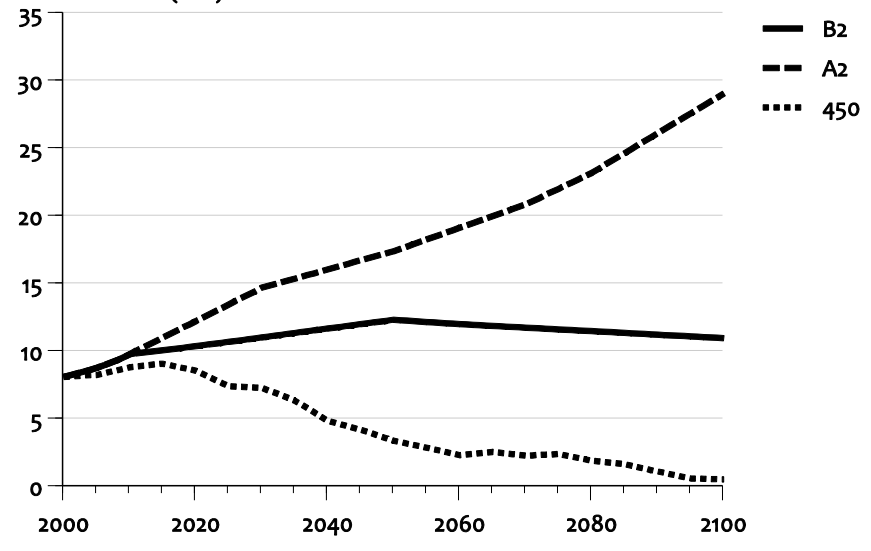


Cumulative discounted damages

as \% of cumulative discounted GDP

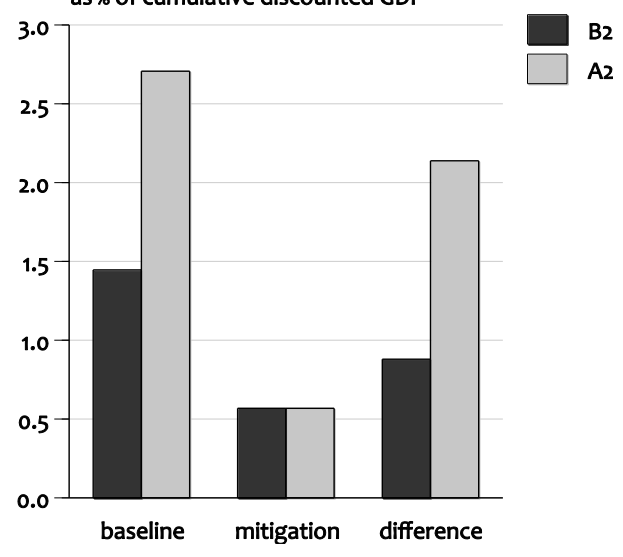


B2 baseline

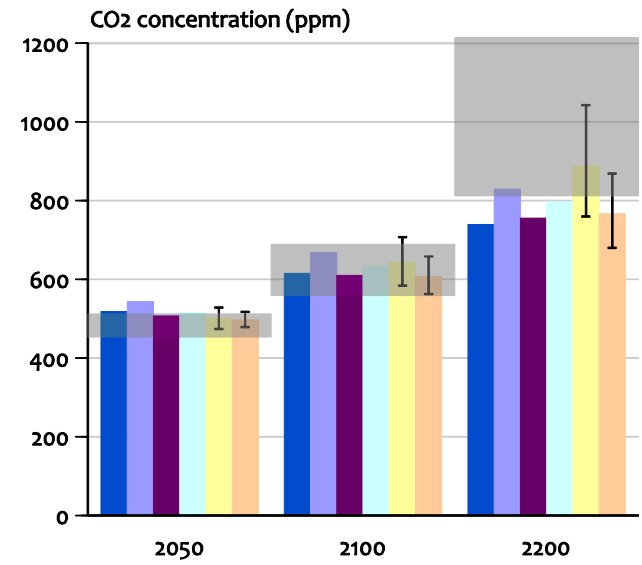

Carbon cycle model according to:

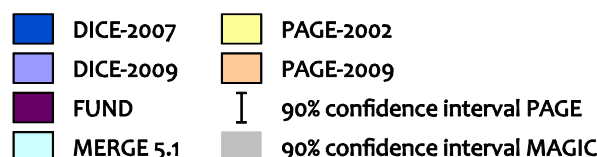

Mitigation scenario

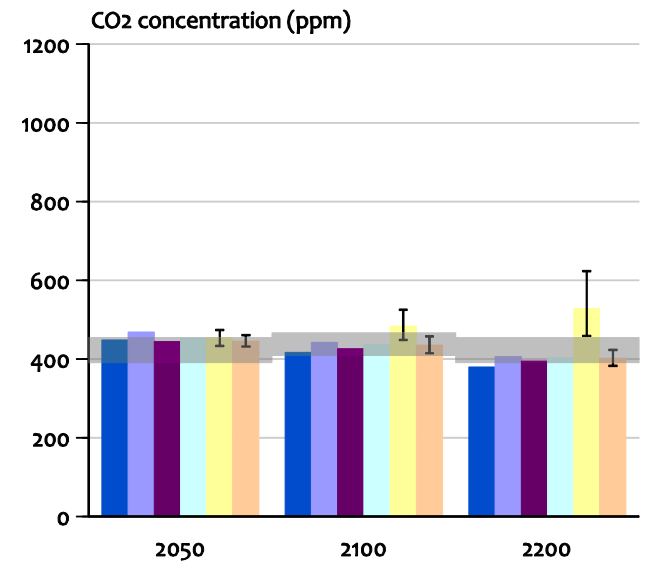


B2 baseline

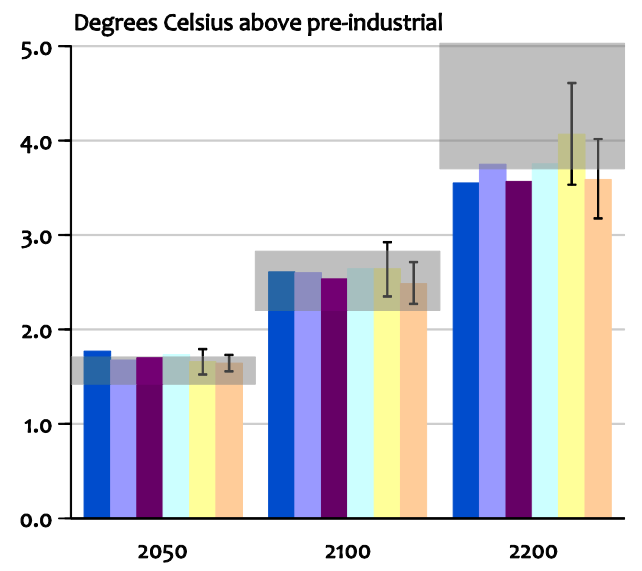

Carbon cycle model according to:

$\square$ DICE-2007

DICE-2009

FUND

$\square$ PAGEO

I $90 \%$ confidence interval PAGE

MERGE 5.1
Mitigation scenario

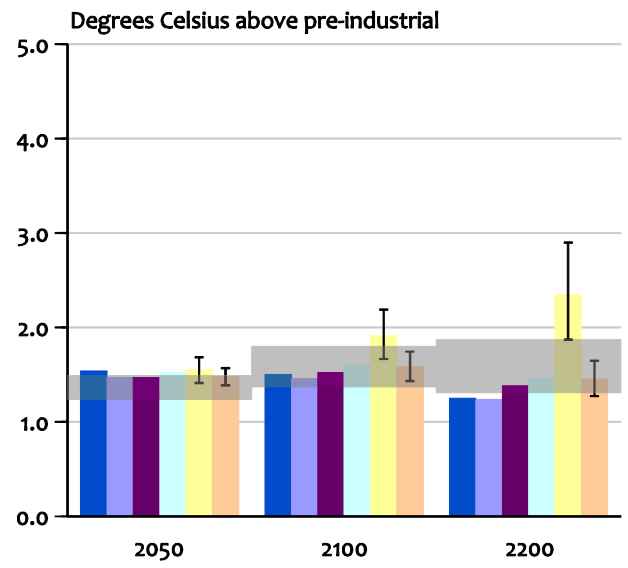


Share of GDP

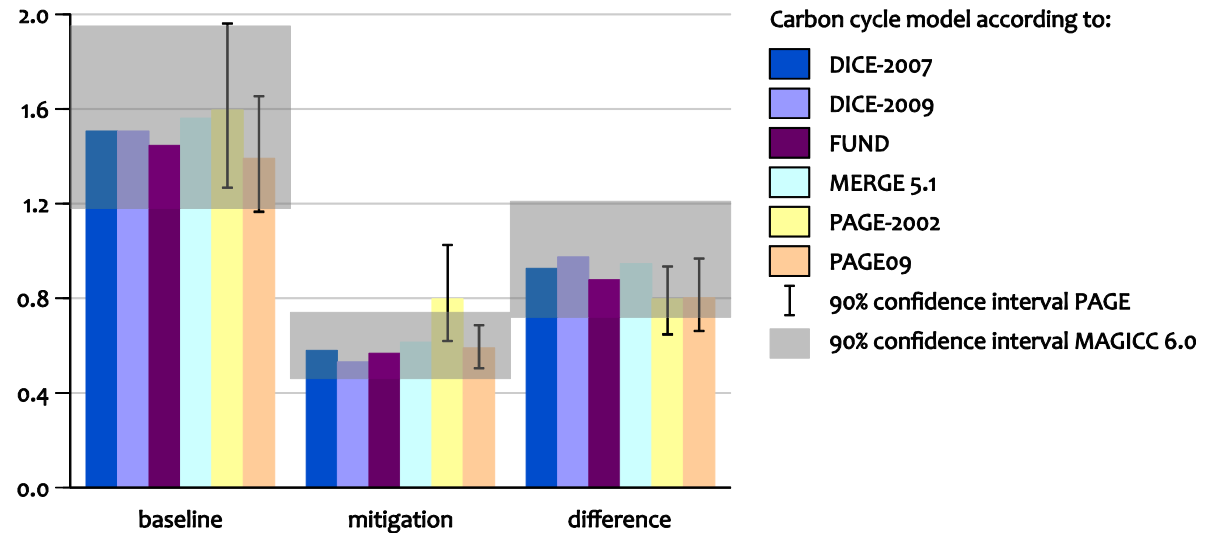


B2 baseline

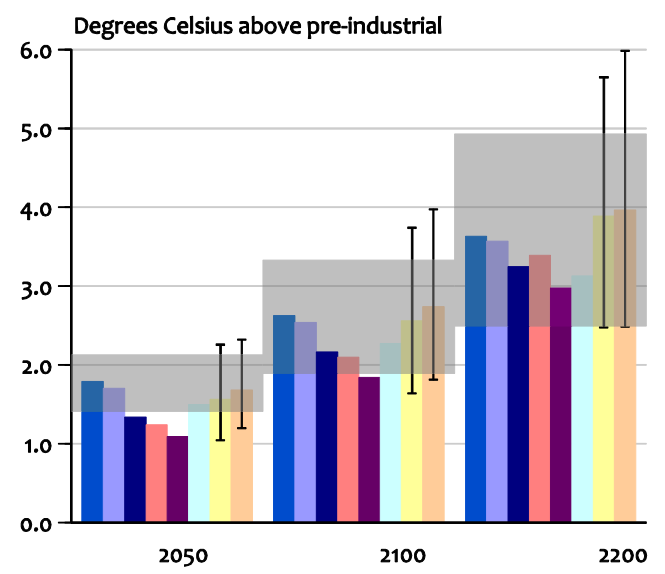

Mitigation scenario

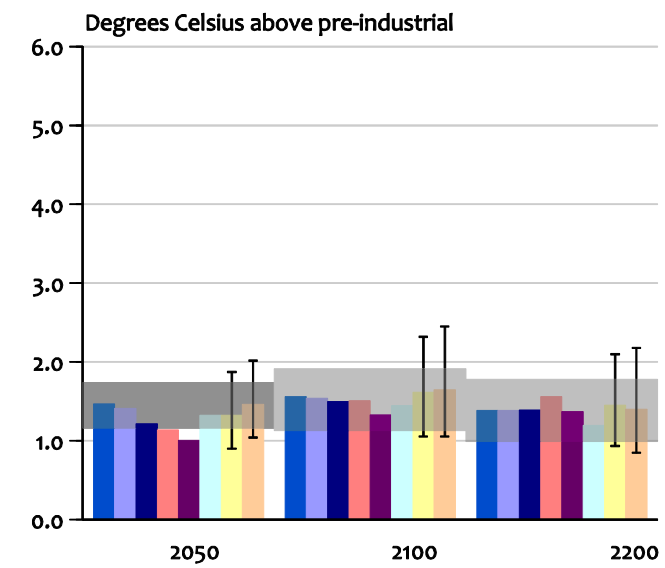

Climate model according to:

$\square$ DICE-2007
$\square$ DICE-2009
FUND 2.8
$\square$ FUND 3.3 (mean)
$\square$ FUND 3.3 (mode)

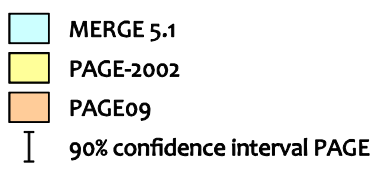

I $90 \%$ confidence interval PAGE

$90 \%$ confidence interval MAGICC 6.0 


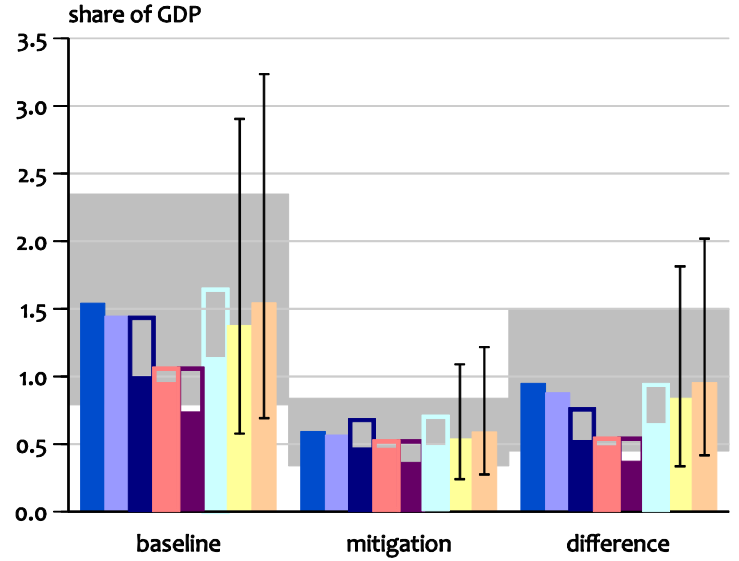

Climate model according to:

$\square$ DICE-2007

$\square$ DICE-2009

FUND 2.8

FUND 2.8 with climate sensitvity of 3.0

FUND 3.3 (mean)

FUND 3.3 (mean) with climate sensitvity of 3.0

FUND 3.3 (mode)

FUND 3.3 (mode) with climate sensitvity of 3.0

MERGE 5.1

MERGE 5.1 with climate sensitvity of 3.0

PAGE-2002

PAGEO9

I $90 \%$ confidence interval PAGE

$90 \%$ confidence interval MAGICC 6.0 
Cumulative discounted damages
as \% of cumulative discounted GDP

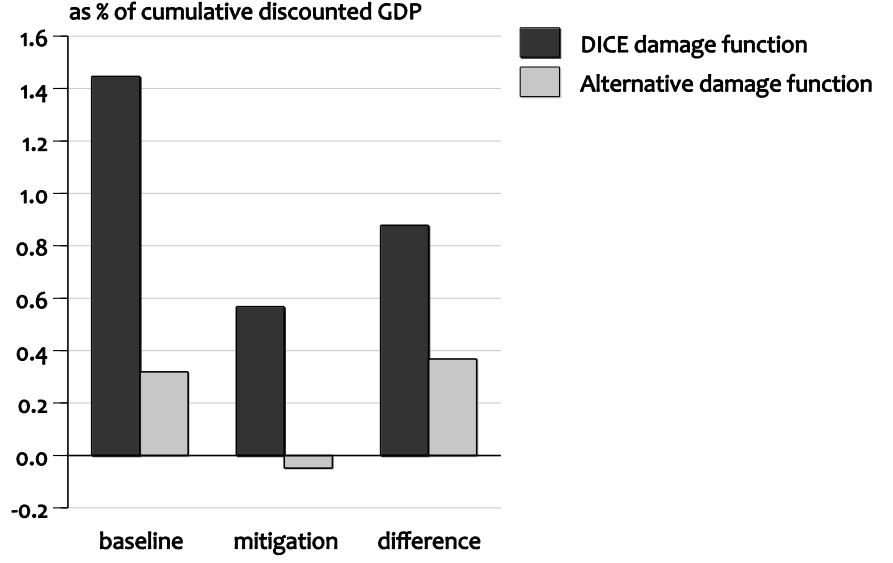


<smiles>[C+]1C[As]1</smiles> 


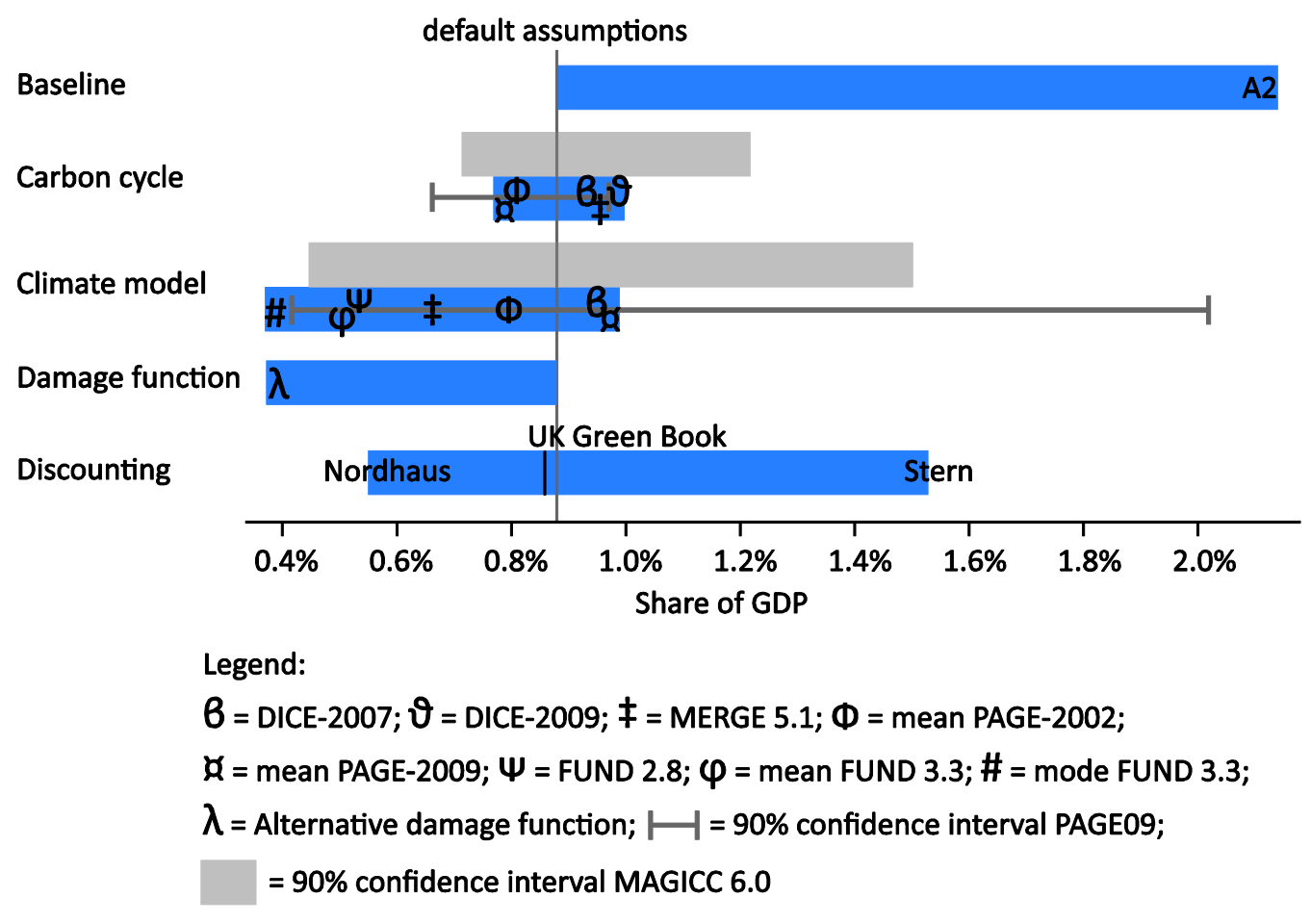




\section{University Library}

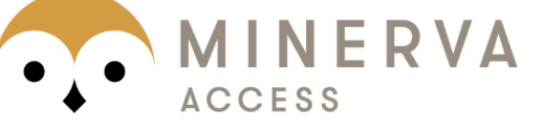

A gateway to Melbourne's research publications

Minerva Access is the Institutional Repository of The University of Melbourne

Author/s:

Hof, AF;Hope, CW;Lowe, J;Mastrandrea, MD;Meinshausen, M;van Vuuren, DP

Title:

The benefits of climate change mitigation in integrated assessment models: the role of the carbon cycle and climate component

Date:

2012-08-01

\section{Citation:}

Hof, A. F., Hope, C. W., Lowe, J., Mastrandrea, M. D., Meinshausen, M. \& van Vuuren, D. P. (2012). The benefits of climate change mitigation in integrated assessment models: the role of the carbon cycle and climate component. CLIMATIC CHANGE, 113 (3-4), pp.897-917. https://doi.org/10.1007/s10584-011-0363-7.

Persistent Link:

http://hdl.handle.net/11343/282654 